\title{
DESCOMPASSOS
}

DA LEGISLAÇÃO

BRASILEIRA

\section{SOBRE O TRABALHO}

DO PROFESSOR

\section{DE LÍNGUAS ESTRANGEIRAS NA EDUCAÇÃO BÁSICA}

\section{DISONANCIAS DE LA LEGISLACIÓN BRASILEÑA SOBRE EL TRABAJO DEL PROFESOR DE LENGUAS EXTRANJERAS EN LA EDUCACIÓN BÁSICA}

\author{
DISSONANCES OF BRAZILIAN LEGISLATION ON THE WORK OF FOREIGN LANGUAGE \\ TEACHERS IN BASIC EDUCATION
}

Décio Rocha*

Universidade do Estado do Rio de Janeiro

RESUMO: Este artigo tem por objetivo promover o debate de políticas governamentais centradas no ensino básico de línguas estrangeiras modernas no Brasil, expressas em documentos oficiais - os Parâmetros Curriculares Nacionais (PCN Ensino Fundamental, PCN Ensino Médio e PCN+). Com base em análise documental como procedimento metodológico, o corpus foi cotejado a reflexões críticas de pesquisadores em Linguística Aplicada voltados para o campo das políticas linguísticas. Dentre os resultados alcançados, destacam-se: (i) as dificuldades criadas por uma legislação que fragiliza o ensino de língua estrangeira na escola; (ii) a qualidade das intervenções de pesquisadores na área que parecem ratificar (ou não) a precariedade das condições de tal modalidade de trabalho; (iii) uma concepção problemática de leitura presente nos documentos consultados.

PALAVRAS-CHAVE: Parâmetros Curriculares Nacionais (PCN). Ensino de língua estrangeira. Trabalho do professor.

RESUMEN: Este artículo tiene como objetivo promover el debate de las políticas gubernamentales centradas en la enseñanza básica de lenguas extranjeras en Brasil que se presentan en los documentos oficiales - los Parámetros Curriculares Nacionales (PCN de la escuela primaria, secundaria y $\mathrm{PCN}+$ ). Con base en el análisis de documentos como procedimiento metodológico, el corpus ha sido confrontado con reflexiones críticas de investigadores en Lingüística Aplicada que actúan en el área de políticas lingüísticas. Entre los resultados obtenidos se destacan los siguientes: (i) las dificultades creadas por una legislación que fragiliza el trabajo de enseñanza 
de lenguas extranjeras en la escuela; (ii) la calidad de las intervenciones de investigadores en el área que logran (o no) aportar una contribución efectiva de modificación de dichas condiciones precarias; (iii) una concepción de lectura problemática presente en los documentos analizados.

PALABRAS CLAVE: Parámetros Curriculares Nacionales (PCN). Enseñanza de lengua extranjera. Trabajo del profesor.

ABSTRACT: This paper aims to analyze the government policies on the teaching of modern foreign languages in Brazilian schools, as expressed in official documents - the National Curriculum Parameters (PCN - Elementary Education, PCN - Secondary Education, and $\mathrm{PCN}+$ ). By making use of documentary analysis as a methodological procedure, we collated the corpus, taking into account theoretical considerations by researchers in Applied Linguistics addressing language policies. The results achieved allow us to raise problems concerning different issues, among which we highlight the following: (i) difficulties are created by a legislation that jeopardizes foreign language teaching in Brazilian schools; (ii) some interventions of researchers in the area seem to corroborate the precarious conditions of such modality of work; and (iii) a problematic conception of reading is present in the documents analyzed.

KEYWORDS: Brazilian National Curricular Parameters (PCN). Foreign language teaching. Teacher's work.

\section{INTRODUÇÃO}

Em consonância com o cenário conturbado que vem caracterizando o país nos últimos tempos ${ }^{1}$, a educação atravessa, neste primeiro semestre de 2016, um período particularmente difícil, que se revela com particular nitidez nos movimentos de greve dos quais participam, dentre outros profissionais, os professores, e também na iniciativa de ocupação de escolas públicas promovidas por estudantes que exigem condições dignas de funcionamento para a educação.

Minha contribuição neste artigo para um debate centrado na Educação Básica, conquanto bastante pontual, parece-me constituir uma questão de particular interesse: com base em diferentes versões dos PCNs, que diagnóstico se faz da situação do ensino de uma língua estrangeira na escola e o que se silencia de tal realidade?2.

Ao tematizar o que é dito e o que se silencia em relação ao ensino de línguas estrangeiras, busco explicitar o papel dos dispositivos acionados nos referidos documentos oficiais de modo a produzir um duplo efeito: primeiramente, muitas das escolhas que são feitas na escola se metamorfoseiam em realidades naturais; em seguida, essas mesmas escolhas naturalizadas por intermédio do apagamento dos dispositivos que as produziram acabam ganhando nuanças "cor-de-rosa" para se tornarem mais palatáveis. Ou seja, o que se dá como realidade essencial já é efeito de dispositivos que, camuflando-se, criam o espaço da naturalidade. Conforme veremos, muitas das dificuldades vividas pela escola como situações inevitáveis e irreversíveis são, na realidade, minuciosamente produzidas por meio da orquestração de dispositivos de diversas ordens.

Para tal fim, dialogo com três documentos oficiais referentes ao ensino de língua estrangeira: PCN Ensino Fundamental, PCN Ensino Médio e PCN+. Em seguida, trago para o debate a voz de pesquisadores em Linguística Aplicada que têm se voltado para a área do ensino de línguas ${ }^{3}$. Uma avaliação final dos dados indicará que as posições assumidas por esses pesquisadores oscilam entre corroborar o que preconizam os documentos oficiais e oferecer alternativas.

\footnotetext{
${ }^{1}$ Resumidamente, refiro-me a manifestações de apoio e de contestação do resultado das eleições presidenciais de outubro de 2014 que reelegeram Dilma Roussef para a presidência da República, situação agravada pelos procedimentos de instauração de uma CPI em função de denúncias de corrupção na Petrobrás; a isso, acrescente-se o processo de impeachment de Dilma Roussef e seu afastamento da presidência em maio de 2016.

${ }^{2}$ Este artigo tomou por base palestra por mim proferida em evento organizado por professores de francês do Colégio Pedro II, Rio de Janeiro, nos dias 10 e 11 de setembro de 2015, intitulado " $2^{\circ}$ ReFLEtindo - O Francês como língua estrangeira escolar: sua trajetória, seu espaço, seus desafios".

${ }^{3}$ Para uma reflexão sobre a presença da Linguística Aplicada no ensino de língua francesa, ver Rocha (2016).
} 


\section{O QUE DIZEM OS PCNs DE LÍNGUA ESTRANGEIRA MODERNA - ENSINO FUNDAMENTAL}

O eixo central dos debates presentes nos PCNs de língua estrangeira moderna no Ensino Fundamental diz respeito ao que deve ser priorizado dentre as quatro habilidades - compreensão / produção orais e escritas. O documento preconiza a ênfase no trabalho de leitura, recorrendo à função desempenhada pela língua na sociedade para sustentar tal opção:

No Brasil, tomando-se como exceção o caso do espanhol, principalmente nos contextos das fronteiras nacionais, e o de algumas línguas nos espaços das comunidades de imigrantes (polonês, alemão, italiano etc.) e de grupos nativos, somente uma pequena parcela da população tem a oportunidade de usar línguas estrangeiras como instrumento de comunicação oral, dentro ou fora do país. Mesmo nos grandes centros, o número de pessoas que utilizam o conhecimento das habilidades orais de uma língua estrangeira em situação de trabalho é relativamente pequeno.

Deste modo, considerar o desenvolvimento de habilidades orais como central no ensino de Língua Estrangeira no Brasil não leva em conta o critério de relevância social para a sua aprendizagem. (BRASIL, 1998, p. 20)

A mesma perspectiva é reiterada ao longo do documento:

Quanto à função social, embora se possa dizer que o Brasil é um país multilíngue, dadas as diversas etnias atuantes em sua formação, é necessário, também, reconhecer que a grande maioria da população escolar vive em um estado de monolinguismo. Exceções são as regiões fronteiriças, algumas comunidades multilíngues de grupos de imigração estrangeira ou de indígenas, e as grandes áreas metropolitanas e turísticas, onde circula um grande número de estrangeiros. Isso significa poder-se contar com apoio muito limitado para o desenvolvimento de habilidades lingüísticas fora da escola, visto que, para a grande maioria da população escolar, a língua estrangeira está fora do contexto da interação familiar, sem possibilidades de contato com parceiros falantes da outra língua e sem nenhum contacto internacional significativo. Possivelmente, essa grande maioria não sente nenhuma necessidade ou desejo de se comunicar em língua estrangeira e a percepção de uma necessidade futura é por demais remota. (BRASIL, 1998, p. 65).

O caráter paradoxal de afirmações como "o Brasil é um país multilíngue" e "a grande maioria da população escolar vive em um estado de monolinguismo" é ainda reiterado quando o locutor sugere um trabalho de conscientização dos alunos "[...] da grande quantidade de línguas que os rodeia, em forma de publicações comerciais, de pôsteres, nas vitrinas das lojas, em canções, no cinema, em todo lugar" (BRASIL, 1998, p. 65). Como se percebe, parece bastante hesitante a situação do brasileiro diante da língua estrangeira: se, no início do volume, falava-se do pouco contato com a língua estrangeira, isso é contraditório com o que é dito adiante.

Outra razão para a ênfase no trabalho com leitura é apresentada nos PCNs: exames de vestibular e de admissão a cursos de pósgraduação cobram exclusivamente a habilidade de leitura em língua estrangeira, "[...] habilidade que o aluno pode usar em seu contexto social imediato" (BRASIL, 1998, p. 20). Ao mesmo tempo, várias são as indicações dos motivos que talvez sejam os mais determinantes para a opção feita pela atividade de leitura:

Deve-se considerar também o fato de que as condições na sala de aula da maioria das escolas brasileiras (carga horária reduzida, classes superlotadas, pouco domínio das habilidades orais por parte da maioria dos professores, material didático reduzido a giz e livro didático etc.) podem inviabilizar o ensino das quatro habilidades comunicativas. (BRASIL, 1998, p. 21).

Tudo se passa, desse modo, como se tais condições não fossem extremamente prejudiciais - se não impeditivas - de um trabalho de leitura, o qual não pode, por razões evidentes, se realizar senão por meio de atividades que envolvam a oralização. O mesmo quadro é trazido ao leitor algumas páginas adiante, quando o locutor apresenta uma síntese da atual situação do ensino de língua estrangeira no país:

Todas as propostas apontam para as circunstâncias difíceis em que se dá o ensino e aprendizagem de Língua Estrangeira: falta de materiais adequados, classes excessivamente numerosas, número reduzido de aulas por 
semana, tempo insuficiente dedicado à matéria no currículo e ausência de ações formativas contínuas junto ao corpo docente. (BRASIL, 1998, p. 24).

Como se percebe, as condições de funcionamento das escolas são naturalizadas - o autor fala das “condições existentes" como se tais condições estivessem dadas de uma vez por todas, em virtude de alguma força que se abatesse irremediavelmente sobre as aulas de línguas estrangeiras. Não se percebe na redação do texto nenhuma forma de resistência a tal quadro, como se a superlotação das salas e a determinação de uma carga horária reduzida para a disciplina representassem tão somente fatores limitantes do ensino/aprendizagem, e não fatores impeditivos de seu pleno exercício. Na verdade, encontramos, sim, no texto dos PCNs uma referência à necessidade de "medidas eficazes" para sanar problemas como os da quantidade, intensidade e continuidade de exposição à língua. No entanto, apesar de se dizer, não sem alguma resignação, que "essas limitações são inaceitáveis" (BRASIL, 1998, p. 66), o documento prossegue em seu afã de estabelecer o que denomina “metas realistas".

Assim, não é sem algum humor que encontramos adiante uma razão "atenuante" para o quadro apresentado: a análise da situação do ensino de Língua Estrangeira no país indica que "a maioria das propostas para o ensino dessa disciplina reflete o interesse pelo ensino da leitura”, ou seja, para além das deficiências que caracterizam nosso sistema de ensino, o fato é que os responsáveis pelo ensino de línguas estrangeiras preferem, em sua maioria, trabalhar exclusivamente a leitura. Uma feliz coincidência.

Para convencer o leitor, o locutor recorre a uma metáfora que, aliás, se tornou bastante conhecida: a metáfora das lentes da máquina fotográfica, segundo a qual se pode utilizar desde uma lente padrão (foco na habilidade de leitura) até uma lente mais abrangente (foco envolvendo outras habilidades comunicativas). No texto, o uso da lente padrão é o que pretensamente garante o acesso de todos, em igualdade de condições, a uma educação linguística dita de qualidade.

Muito claramente se pretende acentuar o lugar das línguas estrangeiras na sociedade de informação e da comunicação em que vivemos, inclusive como "[...] força libertadora tanto em termos culturais quanto profissionais" (BRASIL, 1998, p. 38-39), uma vez que propicia consciência crítica sobre a linguagem.

A tudo isso, acrescentem-se ainda dois outros fatores apontados como dificultadores do trabalho com língua estrangeira: por um lado, a necessidade de garantir a continuidade e sustentabilidade de seu ensino, tendo em vista que não haverá avanços na hipótese de oferecer aos alunos "[...] a aprendizagem de espanhol na quinta série, de francês na sexta e sétima, e de inglês na oitava série" (BRASIL, 1998, p. 20); por outro lado, as reiteradas menções à língua inglesa como "língua do poder econômico e dos interesses de classes" (BRASIL, 1998, p. 40-43), situação hegemônica que se reflete, inclusive, nas referências bibliográficas que dão suporte a esse volume dos PCNs, nas quais encontramos uma obra em francês, uma obra em espanhol, 27 obras em português e... 94 obras em inglês!

\section{O QUE DIZEM OS PCNs DE LÍNGUA ESTRANGEIRA MODERNA - ENSINO MÉDIO}

O texto dos PCNs - Ensino Médio elenca uma série de fatores que dificultam o ensino de língua estrangeira moderna na escola, buscando, desse modo, justificar a "feição monótona e repetitiva" (BRASIL, 2000, p. 25) de tal modalidade de ensino, responsável pela desmotivação de professores e alunos. Assim, apesar de a legislação da primeira metade do século XX já prever o caráter prático do ensino de línguas estrangeiras vivas, o "[...] reduzido número de horas reservado ao estudo", aliado à "[...] carência de professores com formação linguística e pedagógica [...] foram os responsáveis pela não aplicação efetiva dos textos legais” (BRASIL, 2000, p. 25).

Como fator promotor de tal desmotivação, cita-se, ainda, a exemplo do que já se fizera nos PCNs Ensino Fundamental, a hegemonia da língua inglesa nos currículos, o que teria reduzido o interesse pelo aprendizado de outros idiomas, bem como a formação de professores de outras línguas. E mais: a escassez no país de materiais didáticos realmente incentivadores, ou pelo menos de materiais cujo custo os tornasse acessíveis aos estudantes. 
[...] as Línguas Estrangeiras na escola regular passaram a pautar-se, quase sempre, apenas no estudo de formas gramaticais, na memorização de regras e na prioridade da língua escrita e, em geral, tudo isso de forma descontextualizada e desvinculada da realidade. (BRASIL, 2000, p. 26).

Anuncia-se, então, em tom de explícito contentamento, que agora, pelo fato de passarem a integrar a grande área de Linguagens, Códigos e suas Tecnologias, as Línguas Estrangeiras Modernas assumem sua função de "[...] veículos fundamentais na comunicação entre os homens" e de meio de "acesso ao conhecimento" (PCN-Ensino Médio, 2000, p. 26).

Outro trecho que surpreende por sua estrutura concessiva é o que segue:

Embora seja certo que os objetivos práticos - entender, ler, falar e escrever - a que a legislação e especialistas fazem referência são importantes, quer nos parecer que o caráter formativo intrínseco à aprendizagem de Línguas Estrangeiras não pode ser ignorado. (BRASIL, 2000, p. 26).

Como justificar a referida estrutura concessiva introduzida por "embora"? De que modo compreender que um trabalho voltado para as habilidades de entender, falar, ler e escrever possa não contribuir para o que se denomina "caráter formativo intrínseco" a essa modalidade de aprendizagem, que mais adiante é definido como a possibilidade de o aluno "atingir um nível de competência linguística" (BRASIL, 2000, p. 26) que lhe dará condição de acessar informações de vários tipos, além de contribuir para sua formação de cidadão? Como se se tratasse de uma consequência direta do que acaba de ser dito, mais uma vez se insiste na falácia de um aprendizado baseado em conhecimento metalinguístico e no domínio consciente de regras gramaticais.

Imprescindível, pois, "restituir ao Ensino Médio o seu papel de formador" (BRASIL, 2000, p. 27), na voz do legislador. E qual a saída apontada para tal fim? A resposta é direta e concisa: reconsiderar a concepção de ensino de língua estrangeira. Para tal, é preciso levar em consideração os seguintes pontos:

o monopólio da língua inglesa nas escolas e, mais recentemente, a presença da língua castelhana, línguas que inclusive vêm solidificar o compromisso do Ensino Médio com a educação para o trabalho;

o interesse de uma comunidade em ter uma segunda língua estrangeira específica, em caráter optativo, em suas escolas.

O texto alcança um auge de nonsense no trecho a seguir:

Atualmente, a grande maioria das escolas baseia as aulas de Língua Estrangeira no domínio do sistema formal da língua objeto, isto é, pretende-se levar o aluno a entender, falar, ler e escrever, acreditando que, a partir disso, ele será capaz de usar o novo idioma em situações reais de comunicação. Entretanto, o trabalho com as habilidades linguísticas citadas, por diferentes razões, acaba centrando-se nos preceitos da gramática normativa, destacando-se a norma culta e a modalidade escrita da língua. São raras as oportunidades que o aluno tem para ouvir ou falar a língua estrangeira. Assim, com certa razão, alunos e professores desmotivam-se, posto que o estudo abstrato do sistema sintático ou morfológico de um idioma estrangeiro pouco interesse é capaz de despertar, pois torna-se difícil relacionar tal tipo de aprendizagem com outras disciplinas do currículo, ou mesmo estabelecer a sua função num mundo globalizado. (BRASIL, 2000, p. 28).

O que se relata no trecho transcrito parece efetivamente não fazer sentido, configurando-se um caso de texto com elementos coesivos, mas ao qual falta alguma coerência. Senão, vejamos: a primeira incoerência pode ser localizada quando o locutor estabelece uma sinonímia entre centrar o estudo da língua em seu sistema formal e buscar levar o aluno a entender, falar, ler e escrever, na esperança de que o aluno seja capaz de se comunicar em situações reais; porém, prossegue o locutor, o trabalho com essas habilidades acaba sendo reduzido ao conhecimento da gramática normativa, com ênfase na norma culta e na modalidade escrita - situação que já se poderia antever, posto que o ponto de partida dessa reflexão era justamente a ênfase no sistema formal da língua objeto. E acrescenta-se então como fator agravante da situação o fato de ser raro o acesso a um uso efetivo da língua estrangeira, o que 
desmotiva a todos - professores e alunos: afinal, o estudo abstrato do sistema sintático ou morfológico da língua dificilmente pode ser relacionado a outras disciplinas do currículo, tornando-se sem função num mundo globalizado ${ }^{4}$ !

O locutor pensa então em substituir a ênfase das habilidades para as competências que é preciso desenvolver a fim de se alcançar a competência comunicativa, apresentada como o encontro de uma competência gramatical, uma competência sociolinguística, uma competência discursiva e uma competência estratégica (BRASIL, 2000, p. 29). E, nesse ponto, o locutor insiste em dizer que não é suficiente uma competência gramatical que torne possível a construção de frases corretas - como se esse fosse o problema das salas de aulas de língua estrangeira em nosso país - sem desenvolver paralelamente o conhecimento referente à adequação de tais frases a um dado contexto.

O locutor volta então a preconizar a articulação da disciplina de Línguas Estrangeiras com outras disciplinas do currículo e com as possibilidades de coletar informações novas inauguradas pela língua estrangeira e pelas tecnologias modernas.

A reflexão se encerra com mais um parágrafo que deixa a desejar em matéria de coerência textual:

A visão de mundo de cada povo altera-se em função de vários fatores e, consequentemente, a língua também sofre alterações para poder expressar as novas formas de encarar a realidade. Daí ser de fundamental importância conceber-se o ensino de um idioma estrangeiro objetivando a comunicação real, pois, dessa forma, os diferentes elementos que a compõem estarão presentes, dando amplitude e sentido a essa aprendizagem, ao mesmo tempo em que os estereótipos e os preconceitos deixarão de ter lugar e, portanto, de figurar nas aulas. (BRASIL, 2000, p. 31).

Com efeito, no encadeamento de ideias do parágrafo acima transcrito, depreende-se o mesmo tom de nonsense já percebido anteriormente:

(i) vários fatores alteram a visão de mundo de cada povo;

(ii) a língua também se altera para expressar as novas realidades;

(iii) por isso é preciso que o ensino de um idioma estrangeiro se baseie na comunicação real;

(iv) somente por meio de uma comunicação real a aprendizagem terá sentido;

(v) desse modo, os estereótipos e preconceitos deixarão de existir na comunicação real;

(vi) estereótipos e preconceitos também deixarão de existir nas aulas.

Como se percebe, (i) e (ii) estabelecem uma relação de causa e consequência entre acontecimentos e enunciados, sendo reafirmada uma função meramente representacional da língua: primeiro se altera o mundo para, em seguida, alterar-se a língua; (iii) e (iv) vêm reiterar um truísmo que talvez não fosse necessário retomar: se trabalhamos com uma língua estrangeira, é desejável que trabalhemos com situações reais de uso da língua; finalmente, (v) e (vi) colocam em cena uma realidade já mais obscura, pois não fica clara a relação que se pretende estabelecer entre uma aprendizagem assentada em situações reais de uso da língua e o desaparecimento de estereótipos e preconceitos não só na comunicação real, mas também nas próprias aulas.

De tal encadeamento confuso de ideias surge, então, o que se considera "a grande meta do ensino de Línguas Estrangeiras Modernas no Ensino Médio” (BRASIL, 2000, p. 31): entender a comunicação como ferramenta imprescindível de formação profissional, acadêmica ou pessoal no mundo moderno. Uma meta que nos parece tão confusa quanto todo o raciocínio feito anteriormente.

\section{O QUE DIZEM OS PCNs+ SOBRE O ENSINO DE LÍNGUAS ESTRANGEIRAS MODERNAS - ENSINO MÉDIO}

Nos PCN+, reforça-se a ação antagônica ao trabalho com língua estrangeira no Ensino Médio representada por quatro situações já mencionadas anteriormente: a superlotação das salas de aula, a heterogeneidade dos alunos, a carga horária insuficiente destinada

${ }^{4}$ Perguntamo-nos se nas outras duas áreas (Matemática e Humanas) também encontramos uma mesma “obsessão" pelo "interdisciplinar em tempos de globalização"! 
ao ensino de línguas estrangeiras e a deficiência na formação de professores. Tais antagonismos não são, contudo, apresentados como impeditivos do trabalho com LE, mas como situações que exigem a "criação de estratégias" que viabilizem a ação do professor.

Desse modo, faz-se um "convite à produção de estratégias" para lidar com situações variadas:

. grande quantidade de alunos e carga horária insuficiente para a disciplina de língua estrangeira: “[...] é recomendável recorrer ao auxílio de monitores - alunos em nível mais avançado que tenham condições de ajudar os colegas e o professor em atividades individuais e de grupo" (BRASIL, 2002a, p. 108).

. heterogeneidade das classes de língua estrangeira: ressalta-se a importância "[...] de criar estratégias para que as competências e os conteúdos selecionados possam ser desenvolvidos nos três anos do ensino médio” (BRASIL, 2002a, p. 103).

. deficiência na formação dos professores de língua estrangeira: "É, portanto, fundamental repensar estratégias de mudança que permitam a profissionalização do ofício de educador e de professor, bem como a elevação do nosso nível de formação" (BRASIL, 2002a, p. 136).

Como já se poderia esperar, as condições adversas desse ensino se refletem também no trabalho de avaliação:

[...] Todavia, há inúmeros obstáculos materiais e institucionais que impedem que ela [a avaliação formativa] seja efetivamente posta em prática de modo coerente e com continuidade: o número de alunos por classe, a extensão dos programas, o horário escolar, a proposta curricular, a carência de recursos materiais e a formação dos professores. (BRASIL, 2002a, p. 124).

Atualmente, no âmbito do ensino das línguas estrangeiras na escola, a grande dificuldade do processo de avaliação reside:

- na heterogeneidade do conhecimento dos estudantes sobre o idioma;

• no grande número de alunos por sala [...] (BRASIL, 2002a, p. 125).

E logo a seguir, a injunção à "resignação": "[...] é essa a realidade que temos de enfrentar, já que poucas escolas oferecem salasambiente e agrupamento de alunos por níveis de conhecimento, o que facilitaria enormemente o trabalho de professores e alunos" (BRASIL, 2002a, p. 125). Uma resignação acompanhada de uma "expectativa de milagre" a ser operado pelo professor: "A avaliação formativa pressupõe a inclusão; cabe portanto ao professor de língua estrangeira administrar e gerenciar a heterogeneidade de suas classes" (BRASIL, 2002a, p. 126).

O documento faz menção ao prestígio adquirido pela língua inglesa dentre as línguas estrangeiras modernas. Com efeito, são diversas as citações diretas feitas ao inglês, regularmente escolhido como exemplo de língua estrangeira moderna: "É importante saber que o passado do verbo to know é knew e que se trata, portanto, de um verbo irregular" (BRASIL, 2002a, p. 109).

Se a presença do inglêsé, por um lado, algo que se expressa pela maior oferta dessa disciplina nas escolas, por outro, também constitui uma escolha do locutor, que parece não poder se impedir de recorrer a expressões da referida língua, quando, por exemplo, sugere ao professor que as atividades de correção "em pair work" são úteis e produtivas: o recurso ao inglês não se explica por qualquer especificidade técnica da expressão utilizada, a qual poderia com propriedade ser substituída por "em duplas".

O que se preconiza nos PCNs+ é que a ênfase seja atribuída ao trabalho de leitura: dentre as quatro habilidades (entender, falar, ler, escrever), ler parece constituir a saída do ensino de línguas estrangeiras diante do quadro deficiente da escola no país. Porém, se por um lado se enfatiza a leitura, por outro menciona-se a necessidade de atenção a outras habilidades:

Criar diálogos para um texto narrativo, encenar uma peça, redigir e apresentar um telejornal, compreender diálogos de filmes, interpretar verbalmente atividades de mímica, simular situações do cotidiano, completar diálogos, produzir slogans e textos publicitários, traduzir poemas e letras de música - estas são algumas das muitas atividades que podem e devem ser desenvolvidas nas aulas de língua estrangeira, articuladas ou não a 
outras disciplinas do currículo, para mobilizar competências e habilidades necessárias ao desenvolvimento e ao uso prático das diversas funções comunicativas da linguagem. (BRASIL, 2002a, p. 120).

Como se percebe, os dois trechos transcritos são reveladores de duas características importantes dos PCNs+. Em primeiro lugar, faz-se referência ao trabalho oral (leitura de textos pelo professor e pelos alunos, dramatizações, etc.) sem que sejam dados os meios para tal fim (afinal, as turmas de língua estrangeira continuam superlotadas, os alunos constituem grupos heterogêneos e a carga horária destinada à disciplina é insuficiente). Essa mesma situação se repete nos PCNs+em vários outros momentos ${ }^{5}$, ainda que permaneça seu silêncio sobre qualquer modificação do quadro desolador das condições de trabalho.

Em segundolugar, ao indicar a leitura como sendo a tábua de salvação nessa situação aflitiva que é a sala de aula de língua estrangeira, subestima-se, como bem observa Schmitz (2000), a complexidade de um trabalho de leitura: tudo se passa como se, diante da impossibilidade de se fazer qualquer coisa em uma sala de aula superlotada, com alunos de diferentes níveis e professores mal formados, não restasse senão... ler textos!

[...] um bom número dos professores que se formam na maior parte das Faculdades de Letras (especialmente as particulares) em cursos de três anos de duração com dupla habilitação (inglês e português) não teria uma metodologia de ensino de leitura suficientemente amadurecida para ministrar aulas de leitura de textos escritos em língua inglesa. Por isso, a aula de leitura facilmente pode chegar a ser simplesmente um contraproducente exercício de tradução literal. (SCHMITZ, 2008, p. 42).

A crítica do autor efetivamente procede: por que razão seria mais fácil - ou mais possível - trabalhar com leitura em um contexto tão desfavorável como o do ensino de língua estrangeira? As salas de aula estão superlotadas, mas será que o trabalho de leitura dispensaria o momento do trabalho oral? Professores têm uma formação deficiente, mas trabalhar a leitura de textos não implicaria uma formação específica desse professor? São insuficientes as horas destinadas ao trabalho de língua estrangeira nas escolas, mas seria a leitura um trabalho que se poderia realizar com uma carga horária tão reduzida? É difícil responder afirmativamente a questões como essas. Não acredito que o locutor dos PCNs ousasse fazê-lo. Porém, o que se constata é que a leitura é a solução que ele encontra para preencher as (poucas) horas destinadas ao trabalho com línguas estrangeiras nas escolas.

Como último tópico caracterizador das preocupações centrais dos PCNs+, cito a (insistente) referência feita a um trabalho deficitário realizado no campo das línguas estrangeiras modernas. Ao discutir sobre as competências abrangentes a serem trabalhadas em língua estrangeira, por exemplo, fica bastante clara a realização de um trabalho com falhas, incompleto, como se percebe no trecho a seguir: "Perceber que o domínio de idiomas estrangeiros no ensino médio, ainda que se dê de forma parcial, permite acesso a informações diversificadas, a outras culturas e a realidades de diferentes grupos sociais." (BRASIL, 2002a, p. 108, grifos meus).

Com efeito, a ênfase na atribuição de responsabilidades por esse trabalho insuficiente recai invariavelmente sobre o professor e sua formação: “[...] não se pode conceber que professores de Língua Estrangeira assim se autodenominem sem dominarem amplamente sua disciplina, tanto nos aspectos relativos à linguagem escrita como à falada” (BRASIL, 2002a, p. 134).

Nesse sentido, responsabilizando a formação teórica recebida pelos professores na universidade e sua prática necessariamente deficiente, o locutor levanta a hipótese de um professor sem voz na escola, isto é, um profissional cujo saber não tem lugar diante de outros tantos saberes que se tornam hegemônicos:

A concepção tradicional dos professores como aplicadores de conhecimentos gerados pela pesquisa universitária, muitas vezes produzida fora da prática do ofício de professor, tem levado a um enfoque reducionista da profissão. Como decorrência, podemos ser levados a crer que nas universidades podem ser produzidos "conhecimentos sem ações, teorias desvinculadas da prática, saberes sem enraizamento em atores e em sua subjetividade.” ( TARDIF, 2002, p. 236).

\footnotetext{
5 Com efeito, os PCNs+ retomam a importância do trabalho oral ao apresentá-lo com a mesma importância do trabalho escrito (p. 127), reiterando-se a importância das quatro habilidades (p. 115, 116, 122, 123). Ao abordar o tema "Exploração do texto" (p. 115), o locutor chega a acordar lugar central ao trabalho oral.
} 
Outra decorrência dessa visão tradicionalista nega aos profissionais do ensino e às suas práticas o poder que verdadeiramente têm, de produzir saberes autônomos e específicos. É como se o trabalho dos professores fosse permeado por diferentes saberes como, por exemplo, o saber dos peritos, o saber dos funcionários que elaboram os currículos, o saber dos didatas e dos teóricos da pedagogia, o saber produzido pelas disciplinas científicas e transposto para as matérias escolares, o saber oriundo das pesquisas na área da educação, o saber proveniente da sociedade e dos meios de comunicação antigos ou novos - saberes esses que não podem nem devem ser produzidos pelos próprios professores. (BRASIL, 2002a, p. 135).

\section{O QUE DIZEM AS PESQUISAS SOBRE OS PCNs}

Tendo em vista o descompasso apontado nos textos oficiais sobre o ensino de língua estrangeira, pretendo neste tópico recuperar a contribuição de autores que, em relação ao ensino de línguas, oferecem uma apreensão mais reflexiva de muitas das observações presentes nos PCNs. Em suas posições, dividem-se entre os que tendem a ratificar as opções apresentadas pelos PCNs e os que tendem a delas se distanciar. Passo, desse modo, a uma breve apresentação das perspectivas de Rojo e Moita Lopes (2004), Celani (2008), Almeida (2012), Assis-Peterson e Cox (2007), Schmitz (2008), Bohn (2000) e Tílio (2014).

Rojo e Moita Lopes (2004) desenvolvem, na qualidade de especialistas em língua portuguesa e língua estrangeira, respectivamente, um importante debate centrado em dois documentos referentes ao ensino da Área de Linguagens, Códigos e suas Tecnologias: os Parâmetros Curriculares Nacionais para o Ensino Médio (PCNEM) e os PCNs+. Os autores dirigem duas críticas centrais aos documentos:

[...] o grau de generalidade e de hermetismo em relação ao destinatário do primeiro documento, os PCNEM, que acabaram exigindo uma complementação e adequação a seus interlocutores, os professores de Ensino Médio, que resultou nos PCN+;

[...] a incoerência entre as visões de ensino-aprendizagem e de línguagem, língua e discurso presentes nos dois documentos que, deveriam ser complementares. (ROJO; MOITA LOPES, 2004, p. 14-15).

Ao articularem o texto dos PCNEM e o dos PCNs+, indicando tratar-se de vozes nem sempre harmoniosas, os autores também tecem considerações sobre diversos programas/sistemas de avaliação, em especial o Saeb (Sistema de Avaliação da Educação Básica) e o Enem (Exame Nacional do Ensino Médio) - programas governamentais - e um programa estrangeiro, o Pisa (Programa Internacional de Avaliação de Estudantes). São graves as críticas que os autores endereçam aos documentos oficiais, dentre as quais podemos citar a “[...] diversidade eclética de teorias, já impregnadas na cultura de senso comum das escolas” e uma organização do ensino excessivamente disciplinar (ROJO; MOITA LOPES, 2004, p. 35-36).

Dentre as recomendações e considerações feitas pelos autores sobre o ensino de línguas idealizado nos PCNs (Ensino Médio) e PCNs+ de língua estrangeira, quero aqui destacar duas. A primeira delas diz respeito à relevância do estabelecimento de parâmetros para o ensino e às condições em que essa ação deve ocorrer. Dizem os autores:

Parâmetros podem dar uma grande contribuição: apontar direções para propostas pedagógicas, informar a elaboração de material didático e de exames nacionais e colaborar na formulação de currículos universitários de formação de professores etc. No entanto, para que possam verdadeiramente afetar a sala de aula, é necessário investimento maciço na educação de professores em serviço e em formação. (ROJO; MOITA LOPES, 2004, p. $55-56)$.

A segunda ordem de considerações que desejo recuperar em Rojo e Moita Lopes (2004) se refere às "bases realistas" para o ensino de língua estrangeira (nas habilidades de leitura e compreensão oral e de produção escrita e oral), levando-se em consideração "[...] as condições de trabalho em sala de aula, número de alunos nas turmas, número de aulas semanais, grau de proficiência dos professores nos vários usos da linguagem, variedade de material disponível para professor e alunos etc." (ROJO; MOITA LOPES, 2004, p. 47). 
As reflexões de Rojo e Moita Lopes vão ecoar em muitos dos posicionamentos de pesquisadores voltados para o trabalho com língua estrangeira em escolas de educação básica. Eis, por exemplo, como se pronunciam Assis-Peterson e Cox (2007) em relação àquilo que os autores chamam de "bases realistas" para o ensino de línguas:

Na escola pública, os alunos não têm. Falta tudo. O cenário é de malogro; lugar de alunos que não aprendem, de professores que não sabem a língua que ensinam, de pais que não se preocupam com a educação dos filhos e de metodologias que não funcionam. (ASSIS-PETERSON; COX, 2007, p. 10).

Entendo as posições assumidas por Rojo e Moita Lopes de um lado e, de outro, por Assis-Peterson e Cox, como a expressão de perspectivas distintas do problema em foco: com Rojo e Moita Lopes, a certeza de que, apesar de todas as adversidades, os parâmetros oferecem uma contribuição indiscutível; com Assis-Peterson e Cox, a ênfase na urgência de ações da responsabilidade do poder público frente à difícil situação vivida nas escolas. Como veremos adiante, o debate entre as duas perspectivas apontadas prosseguirá na voz de outros tantos pesquisadores.

Inicio com um trecho que reproduzo de entrevista feita com Maria Antonieta Alba Celani, referência segura na área da Linguística Aplicada, particularmente no que concerne ao ensino de língua estrangeira:

[entrevistadora] É importante que esses conteúdos [os conteúdos a ensinar em sala de aula] estejam relacionados às práticas sociais de leitura e escrita?

ANTONIETA Sim. Nos Parâmetros Curriculares Nacionais (PCNs) de Língua Estrangeira, lançados em 1998, do qual sou coautora, recomendamos a ênfase em leitura e escrita, considerando as situações do contexto brasileiro. Fomos massacrados. Diziam que a proposta era elitista, pois excluía a possibilidade de acesso do estudante ao desenvolvimento das quatro habilidades - ler, falar, escrever e compreender. Mas como, sem preparo, o professor pode desenvolver a habilidade de fala com 50 crianças por classe em duas horas semanais? Agora, justamente as práticas de leitura e escrita aparecem como uma necessidade social. (ALMEIDA, 2009).

Apresentada como pedra-de-toque de um trabalho com garantias mínimas de sucesso na escola, a leitura ocupa nos PCNs um lugar especial, tendo em vista as precárias condições que se oferecem ao trabalho da sala de aula, dentre as quais, conforme menciona Celani, encontram-se minimamente as condições (deficitárias) de formação do professor e a quantidade de alunos reunidos por turma. É nesse contexto que se justifica a conveniência da escolha do trabalho com leitura no referido contexto:

[...] em relação à maioria das escolas públicas, tentar ensinar as quatro habilidades ou concentrar a atenção na língua falada seria inviável, considerando-se a falta de infraestrutura geral, o número de alunos por turma, a carga horária da disciplina e também, em muitas escolas, o pouco prestígio da matéria no currículo6. (CELANI, 2008, p. 421, tradução nossa).

Esse mesmo ponto de vista é sustentado por Almeida (2012), que justifica a opção pelo foco na leitura preconizado pelos PCNs por intermédio de três ordens de argumentos: práticos, sociais e educacionais. Os primeiros dizem respeito às já mencionadas condições deficientes das escolas, que impediriam qualquer outra modalidade de trabalho; quanto às razões de ordem social, o autor aponta a falta de oportunidade de, fora da escola, se falar a língua estrangeira; as razões educacionais prendem-se ao fato de exames de língua estrangeira no país exigirem tão somente o domínio da habilidade de leitura, como é o caso do vestibular e dos exames para acesso a estudos de pós-graduação. O autor ainda lembra que, nas escolas, o professor precisa ocupar o lugar de educador, e não de mero instrutor de língua estrangeira, papel que lhe cabe nos cursos de língua.

Almeida (2012) ainda acrescenta considerações sobre as Orientações Curriculares para o Ensino Médio (OCEM), de 2006, e também sobre o Programa Nacional do Livro Didático (PNLD) que, de algum modo, diferentemente do que se enfatiza nos Parâmetros, apontam para a necessidade de outros tipos de atividades para além da leitura. Reconhecendo o mérito da natureza não prescritiva das OCEM, o autor, contudo, lembra que a menção ao trabalho com a prática escrita, leitura e comunicação oral

${ }^{6}[\ldots]$ for the vast majority of public schools, attempting to teach the four skills or to concentrate primarily on the spoken language would be unfeasible given the general lack of infra-structure, class size, frequency of instruction, and in many schools also low prestige as a subject in the curriculum. 
presentes nas Orientações corre o risco de recolocar em cena o antigo - e inoportuno - debate sobre as quatro habilidades. Da mesma forma, Almeida (2012) dirige sua crítica ao PNLD pelo fato de nele se preconizar que os livros sejam acompanhados de um $\mathrm{CD}$ visando à integração das quatro habilidades, exigência que, segundo o autor, fere o caráter não prescritivo das OCEM.

Dentre os pesquisadores que, ao que tudo indica, alinham-se com a perspectiva defendida por Assis-Peterson e Cox, quero aqui recuperar a reflexão de Schmitz. Reconhecendo o mérito do trabalho de Rojo e Moita Lopes (2004), Schmitz (2008) reafirma que, se o preconizado pelos autores não for acatado pelo MEC, nenhum avanço será possibilitado. Em seguida, $\mathrm{o}$ autor se permite ir além da crítica dirigida explicitamente à formação de professores, estendendo-a à necessidade de investimento na infraestrutura das escolas para que estas se tornem efetivos centros multimidiáticos. Com efeito, é preciso que o poder público reconheça o estado de carência das escolas e, obviamente, tome providências a respeito.

Acompanhando o ponto de vista dos pesquisadores que tecem críticas aos PCNs, podemos ainda citar Bohn (2000). Com efeito, contrapondo sua voz à daqueles que, em harmonia com as propostas dos PCNs, fazem elogios ao modo como os Parâmetros foram construídos, Bohn denuncia a postura autoritária do Estado no que diz respeito à metodologia utilizada na construção dos Parâmetros Curriculares Nacionais para o Ensino Fundamental, além de criticar a própria concepção de um Conselho Nacional de Educação. Diz o autor:

Poucas pessoas foram envolvidas [na elaboração dos PCN], e quando este envolvimento foi ensaiado, os prazos de participação foram tão exíguos que em quase nada puderam contribuir para sugerir mudanças substanciais nos documentos propostos. A constituição do CNE (Conselho Nacional de Educação) é outro exemplo de como o Estado autocrático ignora o poder ideológico (enfraquecido) em suas decisões, nomeando para o Conselho pessoas não recomendadas e nem reconhecidas pelos educadores como lideranças educacionais no país. (BOHN, 2000, p. 126).

Concluo esta seção trazendo a perspectiva de Tílio (2014), que considera equivocada a polarização de duas posições em disputa do território das práticas de ensino de língua estrangeira na escola: de um lado, a abordagem instrumental, que preconiza o foco na leitura em língua estrangeira, devendo a língua materna ser convocada para o debate sobre o texto lido; de outro, a abordagem comunicativa, que pressupõe um trabalho com as quatro habilidades. Segundo o autor, a necessidade de se buscar uma via alternativa à referida polarização se deve aos resultados insuficientes de ambas as posições:

[...] mesmo após 15 anos da publicação dos PCN, com livros didáticos voltados especificamente para o ensino de leitura, e diversos programas de Ensino Médio voltados especificamente para esse fim, dado o foco em leitura no vestibular e o ENEM, eu e meus colegas da área de Linguística Aplicada em Inglês em todo o Brasil continuamos recebendo reclamações dos professores da rede pública que recebemos em cursos de pósgraduação ou com quem trabalhamos em nossas pesquisas. Se, por um lado, é verdade que o ensino via abordagem comunicativa não funcionou na escola, por outro lado tais relatos mostram que o mesmo parece ter ocorrido com o foco exclusivo na leitura. (TÍLIO, 2014, p. 928).

Desde sempre fica clara a posição do autor em sua crítica a um certo conformismo presente na expressão daqueles que se limitam a justificar a opção por uma abordagem instrumental por falta de condições da escola para acolher qualquer outro tipo de proposta. Como alternativa, Tílio (2014, p. 941) propõe “[...] um meio termo conciliatório entre as duas abordagens metodológicas que hoje disputam espaço na escola pública brasileira: a abordagem sociointeracional, com foco na compreensão e produção de textos orais e escritos". Diferentemente da posição defendida por Almeida (2012), o caráter conciliatório da proposta de Tílio reside em reconhecer um alinhamento entre a fundamentação teórica dos PCNs, PCNs+ e OCEM, documentos aos quais será possível conjugar a abrangência do PNLD (TÍLIO, 2014). 


\section{6 À GUISA DE CONCLUSÃO: O QUE DIZEMOS NÓS SOBRE O ENSINO DE LÍNGUAS ESTRANGEIRAS NA ESCOLA}

Penso ser necessário inicialmente distinguir responsabilidades de diferentes esferas que se confundem no debate dos problemas enfrentados pelo ensino de línguas estrangeiras modernas na escola básica. Senão, vejamos: (i) o excesso de alunos em sala, a heterogeneidade dos alunos reunidos em uma mesma classe e a insuficiente carga horária atribuída à disciplina dizem respeito à responsabilidade dos sistemas de ensino (diretores e administradores de escola do sistema, órgãos governamentais do sistema público); (ii) a formação deficiente dos professores, a seu turno, já explicita uma deficiência dos cursos de licenciatura existentes no mercado.

Quanto à propalada hegemonia da língua inglesa, seria preciso avaliar até que ponto a presença do inglês no cenário das línguas estrangeiras ensinadas na escola representa efetivamente um fator problemático. Os PCNs parecem ratificar a escolha do inglês como língua estrangeira moderna a ser ensinada nas escolas, segundo o indicam algumas pistas: quando justificam a hegemonia da língua inglesa nas escolas como língua do mundo globalizado da contemporaneidade; quando, por exemplo, suas referências bibliográficas se concentram em autores de língua inglesa; quando mencionam, a título de exemplificação, situações específicas do ensino de inglês; finalmente, quando recorrem a uma expressão da língua inglesa para expressar uma ideia, como se não fosse possível encontrar sua tradução no vernáculo.

A reflexão de alguns autores sobre o que dizem os PCNs é bastante oportuna a esse respeito. Segundo Canevacci (1996 apud ASSISPETERSON; COX, 2007, p. 8), "o processo de globalização não é simplesmente aquele em que as culturas indígenas são modernizadas, mas também aquele em que a modernidade se indigeniza”. Dito de outro modo, se o privilégio do inglês se vincula ao imperialismo americano, sua presença como língua hegemônica implica também sua desterritorialização, tornando-se "[...] um artefato a ser legitimamente 'deformado’ pelos falantes de uma mesma galáxia” (ORTIZ, 2006 apud ASSIS-PETERSON; COX, 2007, p. 8). Tal destino do inglês é também o que motiva Pennycook (2001) a propor que os alunos se apropriem da língua "[...] para formular contradiscursos aos discursos e práticas que promovem desigualdade e dependência" (PENNYCOOK, 1994 apud ASSISPETERSON; COX, 2007, p. 7).

Uma segunda ordem de considerações que aqui faço em relação aos PCNs da área de Linguagem e códigos, em especial no que concerne às disciplinas de línguas (materna e estrangeiras), diz respeito à ênfase em suas deficiências. Com efeito, tal característica não deixa de apresentar um lado positivo, na medida em que explicitar suas próprias deficiências é um procedimento que reafirma a capacidade de autocrítica. Contudo, parece-me que tal crítica se mostra, por vezes, excessiva. Em outras disciplinas que também integram os PCNs, dificuldades também se apresentam, mas não com a mesma insistência: em Educação Física, por exemplo, menciona-se a presença de turmas heterogêneas no Ensino Médio (alunos com diferentes experiências de prática de esportes fora da escola; educação muito diferenciada para meninos e meninas em relação ao uso do corpo) e de "[...] professores leigos que, por não terem completado o ensino médio ou não terem tido acesso ao ensino superior em Educação Física, dispõem de formação precária para sua atuação profissional” (BRASIL, 1998, p. 176-177). A tal característica acrescento que, em relação aos PCNs das demais áreas, os PCNs de Linguagens, Códigos e suas Tecnologias dedicam espaço talvez excessivo ao debate sobre trabalhos interdisciplinares (no interior de uma mesma área e entre áreas). Além disso, as outras áreas parecem também atribuir um peso e uma significação especiais à discussão das estratégias e dos conteúdos de cada disciplina, ao passo que Linguagens, Códigos e suas Tecnologias parece evitar o referido debate, voltando-se prioritariamente para o tema da formação do cidadão.

Tendo em vista os pontos acima referidos, considero que os debates travados na área de Linguagens, Códigos e suas Tecnologias deveriam compreender uma tomada de decisão dentre as alternativas elencadas a seguir: ou a área afirma com todas as letras que as atuais condições do ensino de LE são inadequadas e impeditivas de um trabalho minimamente correto, passando-se a reivindicar o que é necessário para alterar tal quadro desfavorável, ou então se assume que é possível trabalhar em meio a condições muito distantes das ideais, mas se interrompe então o ciclo de ladainhas estéreis que vêm ritmando a reflexão sobre o ensino de línguas estrangeiras modernas. O que parece representar uma saída pouco produtiva é permanecer na verbalização de queixas - em geral, vagas - sem tocar diretamente a ferida que vem inviabilizando melhores resultados no ensino de línguas estrangeiras. 
Considero ser altamente desabonador para a área a não explicitação de uma situação que não é casual e muito menos necessária: o panorama das condições em que se dá o ensino nas escolas não é natural, nem necessário; antes, é meticulosamente produzido para funcionar como vem funcionando ao longo dos anos. Um único exemplo deverá ser suficiente para sustentar o que digo, razão pela qual cito a seguir o Artigo 25 da Lei de Diretrizes e Bases 9.394, de 1996:

Art. 25. Será objetivo permanente das autoridades responsáveis alcançar relação adequada entre o número de alunos e o professor, a carga horária e as condições materiais do estabelecimento.

Parágrafo único. Cabe ao respectivo sistema de ensino, à vista das condições disponíveis e das características regionais e locais, estabelecer parâmetro para atendimento do disposto neste artigo. (BRASIL, 1996).

Como se percebe, a LDB prevê uma ação das "autoridades responsáveis" nos diferentes sistemas de ensino: a análise das condições que determinarão a quantidade de alunos por professor em sala de aula e a carga horária de trabalho. Ora, a pergunta que me ocorre a esse respeito é: que professor tem conhecimento das razões que levaram as autoridades escolares a decidir - e a manter obstinadamente essa decisão - que classes de trinta ou quarenta alunos é o que é possível / desejável na escola? Reiterando minha posição segundo a qual tal condição desfavorável das salas de aula de línguas apresenta-se como meta idealizada pelas autoridades, pude localizar nada menos do que onze projetos de lei versando sobre a fixação de limites ao número de alunos por turma ${ }^{7}$. Grosso modo, neles se propunham turmas de até 25 alunos na pré-escola e nos dois anos iniciais do Ensino Fundamental, e de até 35 alunos nos anos subsequentes até o final do Ensino Médio. Propostas nada revolucionárias, como se pode perceber, mas que nem assim lograram aprovação.

$\mathrm{O}$ argumento a que recorrem muitos dos pesquisadores que defendem o preconizado nos Parâmetros consiste em lembrar que, se o professor se vê em condições de realizar em sala de aula atividades de compreensão e produção orais, por exemplo, indo além do trabalho de leitura, nada o impede de fazê-lo. Ora, se é reconhecido, desse modo, que a compreensão e a produção orais só trariam benefícios à aprendizagem de uma língua estrangeira, não seria papel desse especialista explicitá-lo - e mesmo recomendá-lo - com todas as letras, deixando exclusivamente ao poder público a responsabilidade por sua não execução, como nos tem mostrado a realidade das escolas?

Não posso ser um educador sem ser um político. [...]

Nós nos tornamos capazes de, intervindo no mundo, fazer mais do que nos adaptar ao mundo. [...]

Não é me adaptando à miséria que eu me faço homem, no sentido pleno da palavra, mas é brigando contra a miséria, podendo até morrer na miséria, mas tendo brigado contra a miséria! É isto! (FREIRE, 2014, p. 223-226).

Conforme argumentei anteriormente, mesmo o trabalho de leitura me parece, a rigor, inviável em condições tão adversas. E o risco que se corre não é o anunciado por Pennycook, quando se refere ao necessário esforço para cultivar no aluno uma voz própria, e não "[...] aquela colada à voz britânica nativa ou à voz americana, treinada em aulas comunicativas" (PETERSON; COX, 2007, p. 7), uma vez que na escola definitivamente não se tem conseguido nenhum acesso à língua estrangeira, ficando a tarefa de seu ensino confinada aos cursos de idiomas, aos cursos de línguas ministrados pelas universidades ou às escolas bilíngues ou internacionais (ASSIS-PETERSON; COX, 2007, p. 12-13). Por essa razão, parece-me importante que sejamos mais explícitos em nossas reflexões sobre o ensino de línguas, assumindo que muito do que se vem identificando como fracasso da escola não tem a ver fundamentalmente com a decisão por uma dada metodologia ou com a escolha de uma habilidade a ser praticada em sala; antes, tal fracasso tem coincidido, na realidade, com o grande sucesso das políticas governamentais que se esmeram em tornar ineficaz qualquer iniciativa na área.

${ }^{7}$ Projeto de Lei (PL) 1521/1999, PL 731/1999, PL 640/1000, PL 53/1999, PL 597/2007, PL 720/2007, PLC 230/2009, PL 504/2011, PL 4731/2012, PL 6464/2013, PL 6924/2013. É possível que ainda haja outros projetos da mesma ordem. 


\section{REFERÊNCIAS}

ALMEIDA, D. Antonieta Celani fala sobre o ensino de Língua Estrangeira. Revista Nova Escola, maio 2009. Disponível em: $<$ http://revistaescola.abril.com.br/lingua-estrangeira/ fundamentos/nao-ha-receita-ensino-lingua-estrangeira-450870.shtml>. Acesso em: 14 mar.2016.

ALMEIDA, R. L. T. de. O ensino de inglês como língua estrangeira no contexto das escolas brasileiras: uma visão retrospectiva e prospectiva de políticas e práticas. Revista Brasileira de Linguística Aplicada, Belo Horizonte, v. 12, n. 2, p. 331-348, 2012.

ASSIS-PETERSON, A. A.; COX, M. I. P. Inglês em tempos de globalização: para além de bem e mal. Calidoscópio, v. 5, n.1, p. 5-14, 2007.

BOHN, H. I. Os aspectos 'políticos' de uma política de ensino de línguas e literaturas estrangeiras. Linguagem \& Ensino, Pelotas, v. 3 , n. 1, p. 117-138, 2000 .

BRASIL. Secretaria de Educação Fundamental. Parâmetros curriculares nacionais: terceiro e quarto ciclos do ensino fundamental: língua estrangeira. Brasília: MEC/SEF, 1998.

Secretaria de Educação Fundamental. Parâmetros curriculares nacionais: ensino médio: língua estrangeira. Brasília: MEC/SEF, 2000.

Ministério da Educação. Secretaria de Educação Média e Tecnológica. PCN+ Ensino Médio: Orientações Educacionais complementares aos Parâmetros Curriculares Nacionais - Linguagens, Códigos e suas tecnologias. Brasília: Ministério da Educação, 2002a.

. Ministério da Educação. Secretaria de Educação Média e Tecnológica. PCN+ Ensino Médio: Orientações Educacionais complementares aos Parâmetros Curriculares Nacionais - Ciências da Natureza, Matemática e suas tecnologias. Brasília: Ministério da Educação, 2002b.

. Ministério da Educação. Secretaria de Educação Média e Tecnológica. PCN+ Ensino Médio: Orientações Educacionais complementares aos Parâmetros Curriculares Nacionais - Ciências Humanas e suas tecnologias. Brasília: Ministério da Educação, 2002c.

CANEVACCI, M. Sincretismos: uma exploração das hibridações culturais. São Paulo: Studio Nobel, 1996.

CELANI, M. A. When myth and reality meet: Reflections on ESP in Brazil. English for Specific Purposes - an International Journal, Elsevier, v. 27, n 4, 2008.

FREIRE, P. Pedagogia dos sonhos possíveis. Organização de Ana Maria Araújo Freire. São Paulo: Paz e Terra, 2014.

ORTIZ, R. Mundialização: saberes e crenças. São Paulo: Brasiliense, 2006.

PENNYCOOK, A. The cultural politics of English as an international language. London: Longman, 1994.

ROCHA, D. ReFLEtindo 2014. Da linguística aplicada à didática das línguas: pela diversidade de pesquisas favoráveis ao trabalho com língua estrangeira. Linguagem \& Ensino, Pelotas, v. 19, n. 1, p. 99-123, 2016. 
ROJO, R.; MOITA LOPES, L. P. Linguagens, códigos e suas tecnologias. In: BRASIL. Ministério da Educação. Secretaria de Educação Básica; Departamento de Políticas de Ensino Médio. Orientações Curriculares do Ensino Médio. Brasília: Ministério da Educação, 2004. p. 14-59.

SCHMITZ, J. R.. Uma análise crítica de "Linguagens, códigos e suas tecnologias" de Rojo e Moita Lopes. Calidoscópio (UNISINOS), São Leopoldo, v. 06, p. 37-44, 2008.

TÍLIO, R. Língua estrangeira moderna na escola pública: possibilidades e desafios. Educação \& Realidade, Porto Alegre, v. 39, n. 3, p. 925-944, jul./set. 2014. Disponível em: <seer.ufrgs.br/index.php/educacaoerealidade/article/view/40127>. Acesso em: 26 mar. 2016. 